\title{
Formulation and In-vitro evaluation of sustained release matrix tablet of Metformin hydrochloride
}

\author{
Gaware Ravi U*, Waykar Gayatri R, Yewale Madhuri K, Mhaske Rutuja B, Mhaske Poonam S \\ Vishal Institute of Pharmaceutical Education \& Research. Tal-Junnar, Dist-Pune, Maharashtra 412411
}

\begin{abstract}
The low bioavailability and short half-life of Metformin hydrochloride ( $\mathrm{MH}$ ) make the development of sustained-release forms desirable. Present work involves preparation and optimization of sustained release matrix tablet of MH by direct compression method using HPMC K 100 and ethyl cellulose as a matrix forming polymer. Avicel was added as a direct compaction vehicle to improve the compaction behavior of Metformin which otherwise exhibits poor compaction behavior which again is further increased by its relatively high dose. Hyd rophilic matrix of HPMC alone resulted in initial burst of Metformin release, however when combined with ethyl cellulose drug release was slowed down and thereafter it became optimal at particular concentration of polymers.
\end{abstract}

Keywords: Metformin, HPMC, Ethyl cellulose, sustained release, matrix, tablet.

Article Info: Received 18 March 2019; Review Completed 20 April 2019; Accepted 22 April 2019; Available online 15 May 2019

\section{Cite this article as:}

Gaware RU, Waykar GR, Yewale MK, Mhaske RB, Mhaske PS, Formulation and In-vitro evaluation of sustained release matrix tablet of Metformin hydrochloride, Journal of Drug Delivery and Therapeutics. 2019; 9(3):95-98

http://dx.doi.org/10.22270/jddt.v9i3.2606

*Address for Correspondence:

Mr. Ravi U. Gaware, Vishal Institute of Pharmaceutical Education \& Research, At-Ale Tal-Junnar, Dist-Pune pin-412411

\section{INTRODUCTION}

In recent years, hydrophilic matrices are becoming popular in controlling the release of soluble drugs from solid dosage forms. These systems appear to be one of the most attractive approaches from an economic as well as from the process development points of view. The use of mixtures of polymers represents a potential way of achieving required release properties. Mixtures of different nonionic cellulose ethers have been used to give different viscous efficiencies ${ }^{1}$.

The most widely used polymer for hydrophilic matrices is hydroxypropyl methylcellulose (HPMC). This polymer is considered among the water-soluble polymers. Ethyl cellulose (EC) is considered as a water insoluble polymer due to the hydrophobic substituents (ethyl-). This polymer has been used mainly to form films for the manufacture of oral extended release dosage forms like granules, pellets, microcapsules and film tablets. A second polymer like hydroxypropyl cellulose has been admixed to change the release properties by providing hydrated channels for drug release. Mixtures of different proportions of polymers with different permeation characteristics could provide a wide range of release rates of a drug by changing the diffusivity of the drug through a polymer barrier2, 3 .

Metformin hydrochloride is the first line drug of choice for the treatment of type II diabetes, especially, in overweight and obese people. Metformin helps to improve hyperglycemia primarily by suppressing glucose production by the liver (hepatic gluconeogenesis). The conventional form of Metformin tablets have been found to have many side effects such as gastrointestinal upset, including diarrhea, cramps, nausea \& vomiting. In order to reduce the above mentioned side effects and to enhance patient compliances, sustained release formulation of Metformin was developed. Numerous studies have been reported in literature investigating the HPMC matrices to control the release of variety of drug 4,5 .

In present study an attempt has been made, to formulate the Sustained release matrix tablets of Metformin Hydrochloride and tested for controlled delivery of drug using hydrophilic matrix polymer HPMC in combination with hydrophobic ethyl cellulose, resulting in reduction in the dosing frequency of Metformin and there by its dose related side effects.

\section{MATERIALS \& METHODS}

Materials: Metformin hydrochloride, HPMC, Ethyl Cellulose, Avicel (Microcrystalline cellulose), Magnesium Stearate, Talc.

\section{Preparation of sustained release tablet of Metformin} hydrochloride:

Sustained release matrix tablets containing $500 \mathrm{mg}$ Metformin hydrochloride were prepared by a direct compression method. All ingredients except talc and magnesium stearate were passed through 60 mesh and 
mixed thoroughly in a polybag for few minutes. Thereafter talc and magnesium stearate were passed through 100 mesh to break the clumps and then added to previous mixture in polybag for not more than 5 minutes. The mixture is then compressed using 8 station rotary tablet press at a constant compression force. Different batches were designed in group of three depending upon dissolution pattern of the previous batch.

Table 1: Formulation and composition of SR tablet of MH.

\begin{tabular}{|c|c|c|c|c|c|c|c|c|c|}
\hline \multirow[t]{2}{*}{ Ingredients } & \multicolumn{9}{|c|}{ Batch No } \\
\hline & F1 & F2 & F3 & F4 & F5 & F6 & F7 & F8 & F9 \\
\hline MH & 500 & 500 & 500 & 500 & 500 & 500 & 500 & 500 & 500 \\
\hline HPMC & 150 & 170 & 190 & 150 & 150 & 150 & 170 & 190 & 210 \\
\hline EC & 10 & 10 & 10 & 20 & 30 & 40 & 30 & 30 & 30 \\
\hline Avicel & 150 & 150 & 150 & 100 & 100 & 100 & 100 & 100 & 100 \\
\hline MS & 9 & 9 & 9 & 9 & 9 & 9 & 9 & 9 & 9 \\
\hline Talc & 9 & 9 & 9 & 9 & 9 & 9 & 9 & 9 & 9 \\
\hline
\end{tabular}

MH-Metformin hydrochloride, HPMC- hydroxyl propyl methyl cellulose, EC- ethl cellulose, Avicel- Microcrystalline cellulose, MS- magnesium stearate.

\section{Evaluation of powder properties 6, 7,8:}

The powder mixture obtained from all the batches were evaluated for their physicochemical properties. The angle of repose $(\alpha)$ was determined by the static funnel method and calculated using the formula:

$\tan \theta=\mathrm{h} / \mathrm{r}$

Bulk density (BD) was measured by filling a preweighed 100 $\mathrm{ml}$ glass cylinder to its capacity with the granules and then weighing it. The tap density (TD) was calculated by dividing the fill weight of the powder by its new reduced volume after tapping it 100 times using a tap density apparatus. The compressibility index (CI) and Hausner's ratio (HR) was measured by USP method I using a graduated cylinder. Results are shown in Table 2.

\section{Evaluation of compressed tablets 5, 6, 7, 8:}

Prepared tablets were evaluated for Thickness, hardness, friability, weight variation, disintegration and dissolution. Weight variation was performed by weighing 20 tablets individually, taking average weight and comparing individual weight with the average weight. Hardness of randomly selected tablets was determined by using Erweka hardness tester and was measured in Newtons. Friability was determined by first weighing 10 tablets before placing in Roche friabilator, which was then rotated for 4 minutes at 25 rpm. After dusting tablets were reweighed.

\section{In-Vitro Dissolution test:}

In-vitro dissolution studies were carried out using USP XXI Dissolution Test Apparatus Type II at $75 \mathrm{rpm}$. Dissolution test was carried out for the period of 12 hours using Phosphate Buffer (pH-6.8). $5 \mathrm{ml}$ sample was withdrawn at predetermined time interval up to 12 hours and replaced with same volume of fresh dissolution medium. The withdrawn samples were analyzed by SHIMADZU UV spectrophotometer at $233 \mathrm{~nm}$ using Phosphate Buffer as a blank. Percentage cumulative drug release was calculated 9 , 10,11 .

\section{RESULTS AND DISCUSSION}

Pre compression parameters:

Table 2: Powder properties of different formulations

\begin{tabular}{|c|c|c|c|c|c|}
\hline Formulation & $\begin{array}{l}\text { Angle of } \\
\text { repose }\end{array}$ & Bulk density & $\begin{array}{l}\text { Tapped } \\
\text { density }\end{array}$ & $\begin{array}{l}\text { Carr's } \\
\text { Index }\end{array}$ & $\begin{array}{l}\text { Hausner's } \\
\text { ratio }\end{array}$ \\
\hline F1 & 39.23 & 0.523 & 0.641 & 18.4 & 1.22 \\
\hline F2 & 35.41 & 0.582 & 0.672 & 15.4 & 1.15 \\
\hline F3 & 32.17 & 0.611 & 0.685 & 12.1 & 1.12 \\
\hline F4 & 37.15 & 0.489 & 0.575 & 14.9 & 1.17 \\
\hline F5 & 40.21 & 0.496 & 0.548 & 10.4 & 1.10 \\
\hline F6 & 38.12 & 0.521 & 0.609 & 14.4 & 1.16 \\
\hline F7 & 36.57 & 0.539 & 0.621 & 13.2 & 1.15 \\
\hline F8 & 39.48 & 0.512 & 0.598 & 16.7 & 1.16 \\
\hline F9 & 33.27 & 0.513 & 0.642 & 20.0 & 1.25 \\
\hline
\end{tabular}


Post compression parameters:

Table 3: Tablet properties of Metformin hydrochloride.

\begin{tabular}{|c|c|c|c|c|c|}
\hline Formulation & $\begin{array}{l}\text { Average } \\
\text { weight(mg) }\end{array}$ & Thickness(mm) & $\begin{array}{l}\text { \% drug } \\
\text { content }\end{array}$ & Hardness(N) & \% Friability \\
\hline F1 & 830 & 5.42 & 99.6 & 157 & 0.27 \\
\hline F2 & 849 & 5.48 & 99.3 & 163 & 0.29 \\
\hline F3 & 872 & 5.67 & 98.3 & 169 & 0.33 \\
\hline F4 & 787 & 5.13 & 97.5 & 139 & 0.21 \\
\hline F5 & 803 & 5.23 & 101.3 & 146 & 0.23 \\
\hline F7 & 814 & 5.32 & 103.2 & 148 & 0.27 \\
\hline F8 & 820 & 5.36 & 99.8 & 147 & 0.31 \\
\hline F9 & 843 & 5.41 & 98.7 & 158 & 0.29 \\
\hline
\end{tabular}

In-vitro dissolution studies:

Table 4: Cumulative \% Drug Release (\%CDR)

\begin{tabular}{|c|c|c|l|l|l|l|l|c|c|}
\hline \multirow{2}{*}{$\begin{array}{l}\text { Time(h } \\
\text { rs) }\end{array}$} & \multicolumn{7}{|c|}{ Cumulative \% Drug Release (\% CDR) } \\
\cline { 2 - 10 } & F1 & F2 & F3 & F4 & F5 & F6 & F7 & F8 & F9 \\
\hline $\mathbf{1}$ & 34.1 & 33.6 & 29.4 & 23.8 & 18.9 & 9.6 & 17.1 & 19.4 & 16.3 \\
\hline $\mathbf{2}$ & 57.4 & 53.6 & 49.3 & 39.7 & 25.6 & 13.5 & 23.5 & 24.1 & 19.2 \\
\hline $\mathbf{4}$ & 77.5 & 64.3 & 59.6 & 53.6 & 41.1 & 27.5 & 40.3 & 38.4 & 33.8 \\
\hline $\mathbf{6}$ & 87.3 & 81.2 & 75.6 & 87.2 & 54.7 & 38.8 & 48.6 & 45.6 & 41.9 \\
\hline $\mathbf{8}$ & 96.8 & 92.8 & 88.5 & 89.3 & 76.3 & 59.7 & 71.9 & 69.4 & 56.7 \\
\hline $\mathbf{1 2}$ & 99.1 & 98.7 & 97.5 & 101.2 & 98.7 & 85.1 & 99.3 & 97.8 & 87.6 \\
\hline
\end{tabular}

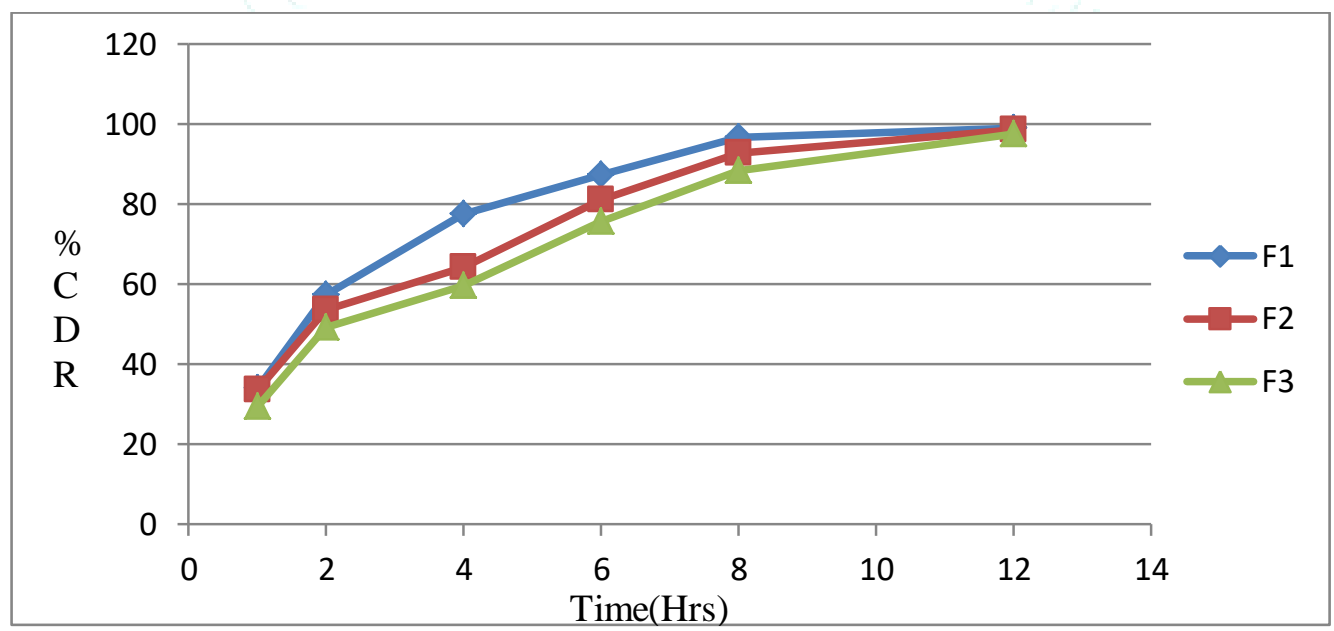

Figure 1: In-vitro dissolution profile F1-F3.

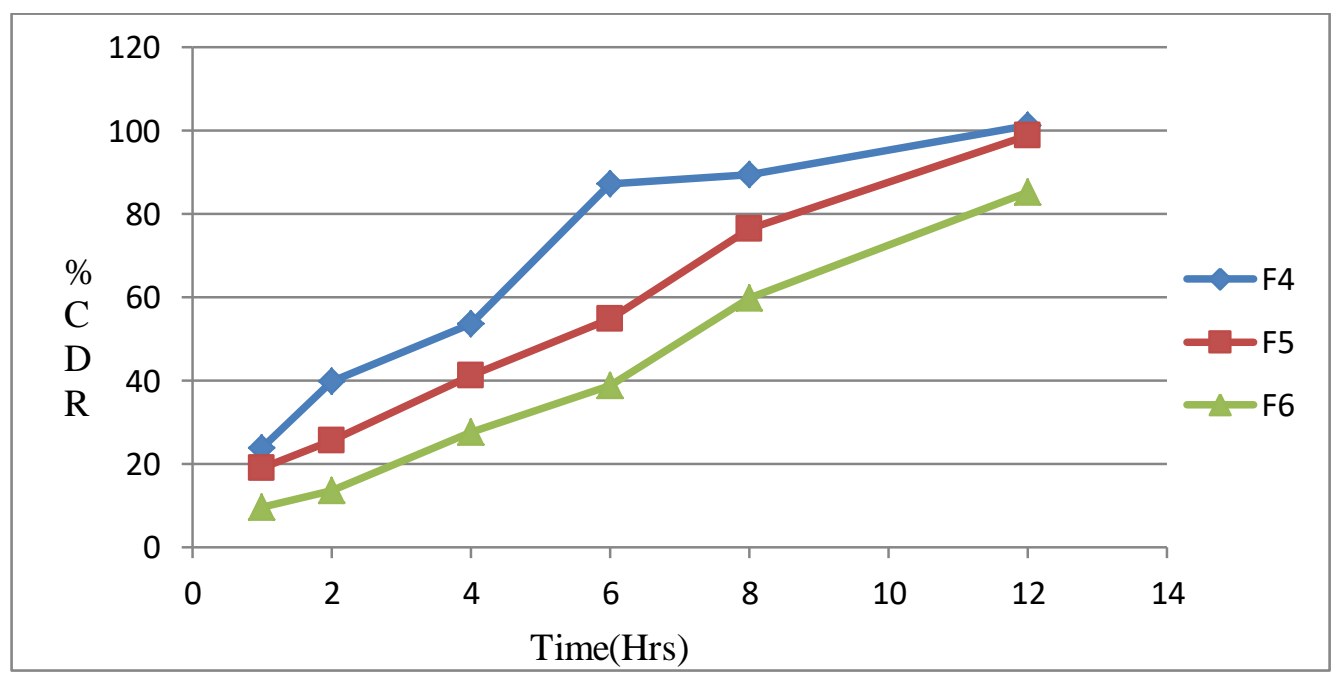

Figure 2: In-vitro dissolution profile F4-F6. 


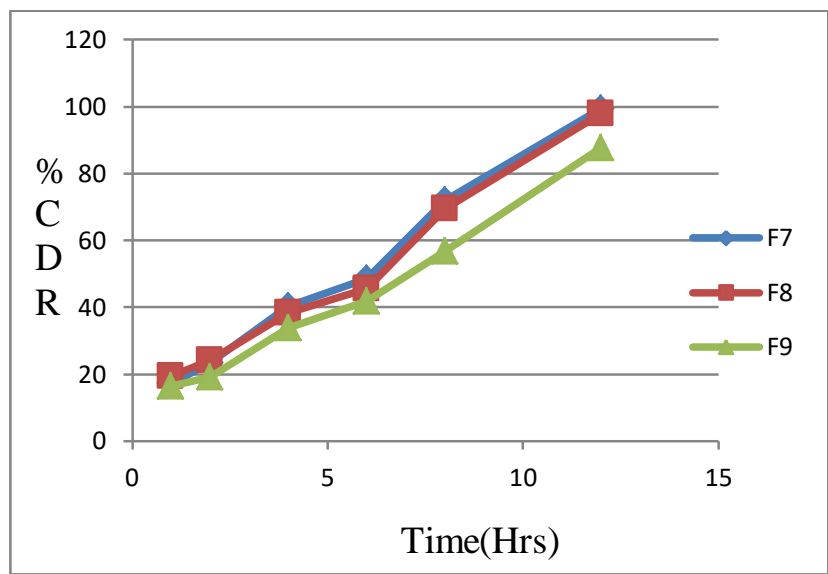

Figure 3: In-vitro dissolution profile F7-F9.

Metformin release profiles from matrix tablet can be considered as being composed of two parts. The first part is the dissolution during the process for the establishment of a fully hydrated gel layer and the second part is the dissolution through this hydrated gel layer. At the beginning, the matrix tablet allows the free dissolution of the Metformin directly in contact with the dissolution medium. After the transition point, in a time between 1.2 and $2.6 \mathrm{~h}$, the second phase controlled by the fully hydrated gel layer. In this phase, the Metformin release goes on mainly by diffusion through the water filled pores.

Formulation F1, F2, F3 showed burst of Metformin release (57\%, 53\% \& 49\% after 2 hours). This can be attributed to time taken by HPMC to form fully hydrated gel, during this time there was no control on drug release although EC was present but its concentration seemed insufficient. This effect seemed to be elevated by Avicel, which also has disintegrant properties due to its capillary structure. Water penetrated through these capillary pores of Avicel and dissolved the drug faster, which resulted in initial burst of drug release. Even after increasing the concentration of HPMC in F2 and F3 (170mg \& 190mg respectively), there was still little improvement in controlling the initial burst of drug release. Once the hydrated matrix of HPMC was formed the drug release was slowed down but still it was relatively faster (87\%, 83\%, 82\% after 6 hours) 12,13 .

On the basis of these results, in the next three batches concentration of Avicel was reduced to minimize its disintegration effects and EC concentration was increased to control the initial drug release until the formation of fully hydrated matrix of HPMC. After these changes F4, F5 \& F6 showed relatively lower initial burst of drug release $(23 \%$, $19 \%, 9 \%$ respectively after one hour), this may be due to incorporation of EC. Hydrophobic nature of EC prevented the penetration of the solvent molecules inside the tablet core, leading to reduced diffusion of the drug from the matrix. This effect was highest in F6 in which $40 \mathrm{mg}$ EC was added. Once the HPMC matrix was formed drug release was fairly uniform but still it was relatively faster. Therefore in the next three batches optimum concentration of EC was taken as $30 \mathrm{mg}$ and was kept constant while concentration of HPMC was varied to get more uniform drug release especially after six hours of dissolution.

Finally, F7, F8, F9 showed considerably uniform drug release (Table 4), although F9 was too slow in drug release.

\section{CONCLUSION}

It can be concluded that a combination of hydrophilic and hydrophobic polymer can be used for extending the release of Metformin hydrochloride for the period of 12 hours. Initially erosion and thereafter Diffusion might be the mechanism for the drug release from hydrophilic and hydrophobic polymer based matrix tablets. Optimized formulation containing HPMC and EC had successfully sustained the drug release up to 12 hours. Thus the sustained release tablet of Metformin hydrochloride can be formulated, evaluated and found to be suitable candidate for prolonging the release of Metformin hydrochloride.

\section{AKNOWLEDGEMENT}

The authors gratefully acknowledge the contributions of Dr. D. D Gaikwad and Dr. S. L. Jadhav, CEO \& Principal VIPER, Ale respectively for constant motivation and encouragement.

\section{CONFLICT OF INTEREST}

The author has no conflict of interest.

\section{REFERENCES}

1. Wise DL, Handbook of Pharmaceutical Controlled Release Technology, 2005; Marcel Dekker, INC., New York and Basel: 211, 435-440, 472-473, and 787-788.

2. Vyas SP and Khar RK, Controlled Drug Delivery, Concepts and Advances, 2002; First edition, Vallabh Prakashan, Delhi: 1-2, 10-12, 156-160.

3. Chien YW, Concepts and system design for Rate controlled drug delivery. In: Novel Drug Delivery Systems 2nd ed. New York: Marcel Dekker; 1992. P. 1-38.

4. $\mathrm{Hu}$ LD, Liu Y, Preparation and in vitro/in vivo evaluation of sustained-release metformin hydrochloride pellets, Eur. J. Pharm. Biopharm. 64 (2006) 185-192.

5. Stepensky D, Friedman M, Srour W, Raz I, Hoffman A, Preclinical evaluation of pharmacokineticpharmacodynamic rationale for oral CR metformin formulation, J. Control. Release 2001; 71:107-115.

6. Siepe S, Lueckel B, Kramer A, Strategies for the design of hydrophilic matrix tablets with controlled microenvironmental pH, Int. J Pharm 2006; 316:14-20.

7. Sung KC, Nixon PR, Skoug JW, Effect of formulation variables on drug and polymer release from HPMC based matrix tablets. Int. J Pharm 1996; 142:53-60.

8. Dunn C.J. and Peters D.H. Metformin: A review of its pharmacological properties and therapeutic use in noninsulin-dependent diabetes mellitus. Drugs., 1995; 49:721749.

9. Defang O, Shufang N, and Wei L., In vitro and in vivo evaluation of two extended Release preparations of combination metformin and glipizide. Drug Dev. Ind. Pharm., 2005, 31, 677-685.

10. Stepensky D, Friedman M, Srour W, Raz I , and Hoffman A., Preclinical evaluation of pharmacokineticpharmacodynamic rationale for oral CR metformin formulation, J. Cont. Rel,2001; 71:107-115.

11. Shaikh N.A, Abidi S.E. and Block L.H., Evaluation of ethylcellulose matrix for prolonged release formulations: Water soluble drugs: acetaminophen and theophylline. Drug Dev. Ind. Pharm., 1987; 13:1345-1369.

12. Colombo R, Bettini P.S, Peppas N.A., Swellable matrixes for controlled drug delivery: gel-layer behavior, mechanisms and optimal performance, Pharm. Sci. Technol. Today., 2000; 3:198-204.

13. Siepmann J, Kranz H, Bodmeier R, and Peppas NA., HPMCmatrices for controlled drug delivery: a new model combining diffusion, swelling, and dissolution mechanisms and predicting the release kinetics. Pharm Res., 1999; 16:1748-1756. 